\title{
Effects of inorganic salts concentration and alternative plant growth regulators on the in vitro organogenesis of a new hybrid Cymbidium
}

\author{
ALEXANDER S. LUKATKIN ${ }^{1 *}$, EvgeniJ V. MOKSHIN ${ }^{1}$, \\ EkATERINA V. BOLShaKova ${ }^{1}$, JAIme A. Teixeira da Silva ${ }^{2 *}$ \\ ${ }^{1}$ Ogarev Mordovia State University, Saransk, Respublika Mordoviya, Russia \\ ${ }^{2}$ Independent, Kagawa-ken, Japan
}

\begin{abstract}
Hybrid Cymbidium is an important ornamental resource as an orchid pot plant and in cut flower markets, so any protocol that can lead to its improved productivity in vitro is always welcome. Based on a cultivar "Memoria Amelia Earhart" that has not been yet studied, the effects on in vitro organogenesis in response to diluted Murashige and Skoog (MS) medium inorganics and plant growth regulators [PGRs: Epin-Extra ${ }^{\circledR}$ (24-epibrassinolide, 24-EpiB), Ribav-Extra ${ }^{\circledR}(\mathrm{RE})$, kinetin (KIN), thidiazuron (TDZ), 6-benzyladenine (BA), and indole-3-acetic acid (IAA)], either alone or as combinations between cytokinins and IAA, were assessed. Whole protocorm-like bodies (PLBs) served as the initial explant source. While full-strength MS medium benefited shoot growth, half-strength MS was optimal for rooting and PLB formation. The optimum concentrations of 24 -EpiB were $10^{4} \%$ and $10^{5} \%$ for shoot growth and $10^{6} \%$ for PLB multiplication, and the maximum shoot growth was induced by RE at $10^{4} \%$ and BA at $4.4 \mu \mathrm{M}$ or $13.3 \mu \mathrm{M}$. The simultaneous application of a cytokinin and IAA in MS had the greatest impact on PLB-related parameters. The number of PLBs per explant was improved by $11.6 \mu \mathrm{M}$ KIN and $2.9 \mu \mathrm{M}$ IAA, while $0.5 \mu \mathrm{M}$ KIN and $2.9 \mu \mathrm{M}$ IAA improved PLB size. The number of regenerated shoots was maximum in MS medium supplemented with $10^{9} \mu \mathrm{M}$ TDZ and $2.9 \mu \mathrm{M}$ IAA, whereas the longest shoots formed in MS medium supplemented with $2.2 \mu \mathrm{M}$ BA and $2.9 \mu \mathrm{M}$ IAA. Using well-explored and unexplored PGRs, we devised an effective in vitro PLB-to-plantlet regeneration protocol for the hybrid Cymbidium "Memoria Amelia Earhart".
\end{abstract}

Key words: benzyladenine, growth, kinetin, mineral salts, protocorm-like body, regeneration, thidiazuron

\section{Introduction}

The Orchidaceace is the largest plant family with 25000-35000 species (Sarmah et al., 2017), and the second most popular cut flower and potted floricultural crop (Albert et al., 2010; Hossain et al., 2010). Detailed global market statistics for the floricultural industry over the past decade are not easily available. Orchids are divided into three groups: epiphytes, terrestrial orchids, and saprophytic orchids (Hossain et al., 2013). Many commercial Cymbidium cultivars are hybrids of different colors (Albert et al., 2010) that often take several years to flower (Kostenyuk et al., 1999). Micropropagation, which is the most commonly used form of propagation for hybrid Cymbidium, has been explored for this orchid genus (Teixeira da Silva, 2013a).

The mineral composition of the medium affects the in vitro production of hybrid Cymbidium protocorm-like bodies (PLBs). Generally, low concentrations of inorganics tend to favor PLB production (Teixeira da Silva et al., 2005), while a high concentration of organics positively influences the in vitromultiplication of Cymbidium pendulum protocorms and maximizes the production of shoots and plantlets (Kaur and Bhutani, 2012). Morel (1960) first produced in vitro cultures of hybrid Cymbi-

\footnotetext{
* Corresponding authors: ${ }^{1}$ Ogarev Mordovia State University, Saransk, Respublika Mordoviya, Russia; e-mail: aslukatkin@yandex.ru;

${ }^{2}$ Independent, Kagawa-ken, Japan; e-mail: jaimetex@yahoo.com
} 
dium, while Fonnesbech (1972) first estimated the importance of plant growth regulators (PGRs) in that process, especially the role of auxins and cytokinins (CKs). Using a wide range of PGRs, Teixeira da Silva (2014) showed that only five out of 26 PGRs were able to improve PLB production and show better results than those previously reported. Among PGRs, the most efficient CKs were 6-benzyladenine (BA) and kinetin (KIN) while thidiazuron (TDZ) favored shoot production. The absolute concentration of any single PGR and its relative amount when used with another PGR can be used to manipulate the organogenic outcome in the hybrid $C y m b i$ dium (Teixeira da Silva and Tanaka, 2006) and other Cymbidium species such as Cymbidium faberi (Tao et al., 2011) or Cymbidium goeringii (Park et al., 2018). Abiotic factors (Teixeira da Silva et al., 2006a) and biotic factors (Teixeira da Silva et al., 2006b) can affect the outcome of PLB formation. These differential responses are most likely related to the biochemical pathways within Cymbidium plants (Albert et al., 2010). Despite these advances, the response of hybrid cultivars and Cymbidium ensifolium (Chang and Chang, 1998; Chang and Chang, 2000) to in vitro conditions remains cultivardependent and most conditions related to the medium inorganic concentration and choice of PGRs need to be optimized for each genotype.

Currently, a large number of PGRs, such as natural PGRs or growth hormones, are used for the in vitro clonal propagation of plants. Natural PGRs, which can be used in low concentrations and are non-toxic to plants and to the environment, are a complex of bioactive compounds of plant origin or products derived from the metabolism of microorganisms. A natural PGR RibavExtra $^{\circledR}$ (RE; "Selhozekoservis", Moscow, Russia) is a product of the metabolism of mycorrhizal fungi isolated from ginseng (Panax ginseng C.A. Mey) roots. It is a $60 \%$ alcohol extract that contains numerous natural amino acids and biologically active substrates. Usually, $\mathrm{RE}$ is used in the field or greenhouses for seed treatment, spraying plants, or processing cuttings. This preparation stimulates the synthesis of phytohormones, growth processes, and can increase resistance to stressors such as an increased tolerance of maize plants to high $\left(45^{\circ} \mathrm{C}\right)$ and low $\left(3^{\circ} \mathrm{C}\right)$ temperature stress (Lukatkin and Pogodina, 2012) and of wheat plants to heavy metals (Gruznova et al., 2018). When used at $10^{5} \%$, during the in vitro clonal propagation of carnation (Dianthus caryo- phyllus L.), RE significantly stimulated shoot growth and significantly increased the number of internodes/shoot at $10^{6} \%$ (Lukatkin et al., 2017).

Epin-Extra ${ }^{\circledR}$ ("NEST-M", Moscow, Russia) contains $50 \mu \mathrm{M}$ of 24 -epibrassinolide (24-EpiB) and is used in the field or under greenhouse conditions for seed conditioning, spraying plants, or processing cuttings. Brassinosteroids (BRs) are a group of phytohormones that influence growth, seed germination, rhizogenesis, and senescence and confer abiotic stress tolerance in plants (Yu et al., 2019). In particular, 24-EpiB is among the three bioactive BRs that are extensively used in physiological and experimental studies, where 24-EpiB differentially modulates antioxidant defense system components in stressed plants (Vardhini and Anjum, 2015). Maize or wheat seeds treated with 24-EpiB showed enhanced tolerance to both high and low temperature and heavy metals (Lukatkin et al., 2013a; 2013b; Bashmakov et al., 2016). In in vitro carnation, 24-EpiB in Murashige and Skoog (MS) medium (Murashige and Skoog, 1962) resulted in better shoot growth, shoot multiplication, and number of internodes/shoots of regenerated plants than obtained from untreated controls. Moreover, it was used to control hyperhydricity in in vitro carnation cultures (Lukatkin et al., 2017). 24-EpiB inhibited PLB formation in another hybrid Cymbidium cultivar (Teixeira da Silva, 2013b) but enhanced growth (improved rooting) in highbush blueberry (Kudryashova et al., 2012).

In this study, we aimed to establish, based on previous knowledge of other Cymbidium species and hybrids, a suitable in vitro propagation protocol for an asyet unexplored hybrid Cymbidium cultivar, "Memoria Amelia Earhart", which is a highly decorative ornamental Cymbidium hybrid that blooms from late winter to summer. To induce in vitro organogenesis, we applied different concentrations of BA, KIN, and TDZ, in combination with $2.9 \mu \mathrm{M}$ IAA, and also assessed the effectiveness of two new PGRs, Ribav-Extra ${ }^{\circledR}$ and Epin-Extra ${ }^{\circledR}$.

\section{Materials and methods}

\section{Plant material and PGRs}

We obtained Cymbidium 'Memoria Amelia Earhart' (syn. $C$. Hazel Tyers $\times C$. devonianum) plants propagated in vitro from the Main Botanical Garden of the Russian Academy of Sciences (RAS). The PGRs used were BA (ICN Pharmaceuticals, Inc., Costa Mesa, USA), KIN 
(Alfa Aesar, Heysham, UK), TDZ (Schering, Berlin, Germany), IAA (Alfa Aesar), Ribav-Extra ${ }^{\circledR}$ ("Selhozekoservis", Moscow, Russia) and Epin-Extra ${ }^{\circledR}$ (NEST-M, Moscow, Russia).

\section{Micropropagation conditions}

Formicropropagation, weused whole individual PLBs of similar size (3-5 mm). Moreover, explants (PLBs) were planted onto MS medium (Murashige and Skoog, 1962) (final $\mathrm{pH}=5.6-5.8$ after autoclaving before being solidified with $0.7 \%$ microbiological agar-agar (SigmaAldrich, St. Louis, MI, USA). To this medium, 0.15\% activated charcoal (Merck KGaA, Darmstadt, Germany) was added based on the recommendation of Teixeira da Silva (2013c). The first set of experiments diversified the basal concentration of MS micro- and macro-nutrients (full-strength MS; $1 / 2 ; 1 / 4 ; 1 / 8$ dilutions), whereas the second set of experiments tested different PGRs individually in MS: BA (from 0.4 to $17.8 \mu \mathrm{M}$ ), RibavExtra $^{\circledR}$ (from $10^{7}$ to $10^{2} \%$ ), and Epin-Extra ${ }^{\circledR}$ (from $10^{7}$ to $\left.10^{2} \%\right)$. The control in all treatments was PGR-free fullstrength MS medium. The third set of experiments tested different CKs containing 2.9 $\mu \mathrm{M}$ IAA in MS: BA from 0.4 to $17.8 \mu \mathrm{M}$, TDZ from $10^{9} \mathrm{M}$ to $100 \mu \mathrm{M}$, and KIN from 0.5 to $18.6 \mu \mathrm{M}$.

\section{Culture conditions}

In vitro cultures were grown in glass jars (diameter $=50 \mathrm{~mm}$, height $=70 \mathrm{~mm}$, volume $=80 \mathrm{ml}$ ) for six weeks in a tissue culture chamber at $22 \pm 2{ }^{\circ} \mathrm{C}$, illuminated by cold white fluorescent lamps (TLD 36W/89, Philips, Russia) under a 16 -h photoperiod and at $120 \mu \mathrm{mol} \cdot \mathrm{m}^{2} \cdot \mathrm{s}^{-1}$ photosynthetic photon flux density (PPFD) (illuminance $=\sim 3000 \mathrm{~lx}$ ). After six weeks, we measured shoot length (length of the lamina without PLBs), the number and size (diameter) of PLBs, and the number and length of roots.

\section{Acclimatization}

Plants from different treatments (90 in total), which developed an average of 2-3 roots, were removed from medium and washed, and then the basal parts of plantlets were placed in a solution of IAA at two concentrations ( 0.6 or $5.7 \mu \mathrm{M}$, based on initial trials) for 15 or $30 \mathrm{~min}$ for conditioning before planting in soil. Control plants were treated with tap water, and plants were planted in plastic cups containing $150 \mathrm{~g}$ of a mixture of ground leaves, peat, coal, and pine bark $(3: 1: 1: 1 \mathrm{v} / \mathrm{v})$, and then covered with a perforated plastic film to maintain humidity during acclimatization for 3-4 weeks before transferring them to a greenhouse. The plants were then grown at $22 \pm 2{ }^{\circ} \mathrm{C}$ and illuminated by cold white fluorescent lamps (TLD 36W/89, Philips, Russia) under a $16-\mathrm{h}$ photoperiod and at $120 \mu \mathrm{mol} \cdot \mathrm{m}^{2} \cdot \mathrm{s}^{-1} \mathrm{PPFD}$.

\section{Statistical analysis}

Each trial included 10 biological replicates (in vitro explants) for each treatment, and all experiments were conducted in triplicate. Both means and standard errors were calculated using Microsoft Excel 2010 and Biostat Statistica v. 2.6. Differences between means were assessed by Tukey's multiple range test at $P \leq 0.05$.

\section{Results}

\section{Medium mineral composition: \\ effects on explant regeneration}

Organogenesis (the formation of PLBs, shoots, and roots) was affected by the dilution of MS medium (Fig. 1), and diluting full-strength MS to $1 / 2,1 / 4$, and 1/8 MS significantly stimulated PLB production (Fig. 1A). We observed a similar trend in the number of shoots and roots with $1 / 2$ and $1 / 4$ MS being significantly superior to $1 / 8$ MS and full-strength MS (Fig. 1A). Full-strength MS medium had a beneficial effect on shoot growth, while halfstrength MS was optimal for root formation (Fig. 1B).

\section{Individual PGRs influence Cymbidium organogenesis in vitro}

$\mathrm{RE}$ and Epin-Extra ${ }^{\circledR}$ (24-EpiB) induced the formation of new PLBs and shoots (Fig. 2). When 24-EpiB was used, the maximum number of PLBs formed at a concentration of $10^{6} \%$ (17.54 PLBs/explant) (Fig. 3A), while maximum shoot length ( 13.43 and $11.78 \mathrm{~mm}$ ) was observed at a concentration of $10^{4} \%$ and $10^{5} \%$, respectively (Fig. 3B). RE did not stimulate PLB formation more significantly than the control (6.2 vs $5.2 \mathrm{PLB} /$ explant) (Fig. 4A) but it significantly stimulated shoot length (20.21 mm vs $6.87 \mathrm{~mm}$ ) (Fig. 4B). BA, when applied alone, significantly stimulated the formation of more PLBs per explant $(6.6 \mathrm{PLBs} /$ explant at $6.7 \mu \mathrm{M})$ and shoot length (14.89 and $15.54 \mathrm{~mm}$ at 4.4 and $13.3 \mu \mathrm{M}$, respectively) compared to the control (Fig. $5 \mathrm{~A}$ and Fig. 5B, respectively). 

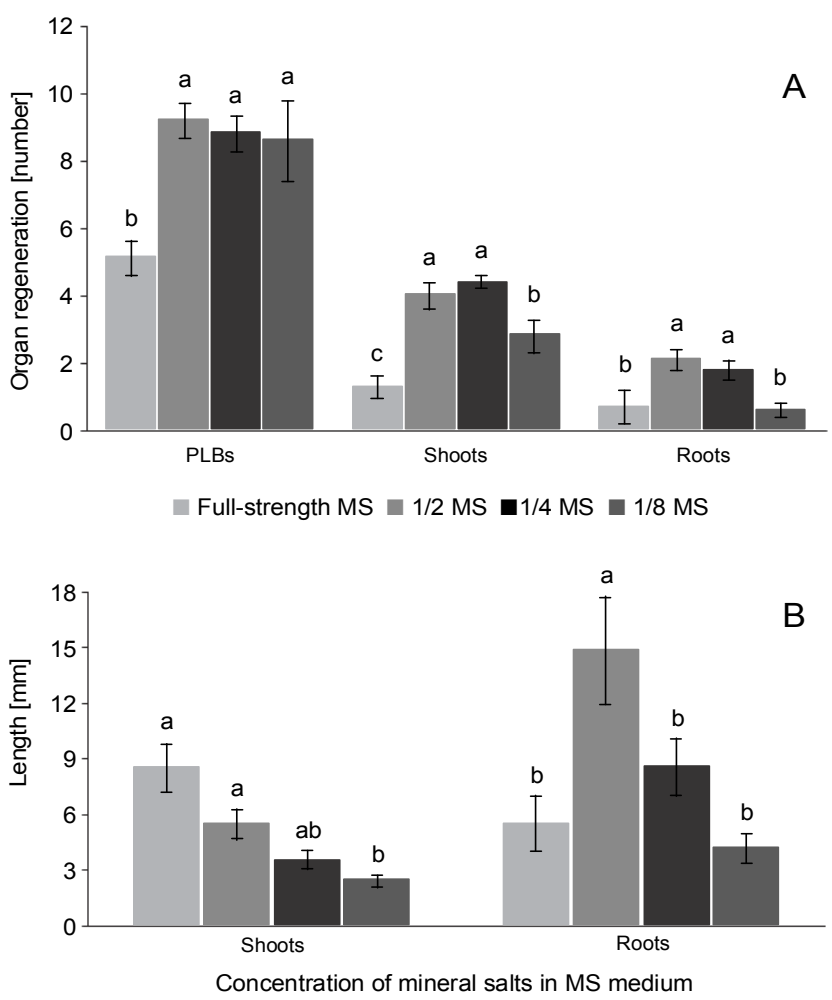

Fig. 1. Organogenesis in Cymbidium hybridum explants on an agarized medium with different dilutions of MS basal medium; bars indicate SE; different letters indicate significant differences at $P \leq 0.05$ (Tukey's multiple range test, $n=10$ )
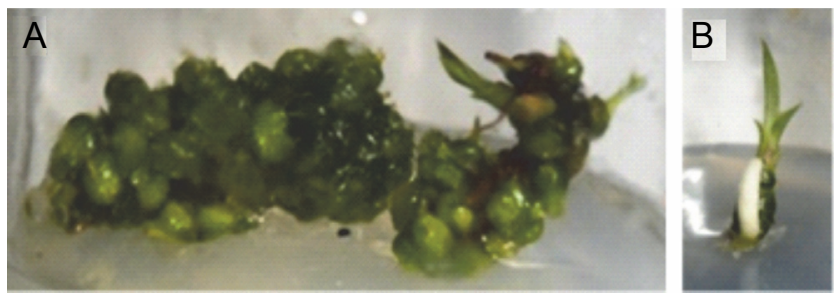

Fig. 2. Organogenesis in Cymbidium hybridum on MS medium supplemented with PGRs. A) formation of PLBs on medium supplemented with $10^{-6} \%$ Epin ${ }^{\circledR}$-Extra; B) shoot growth on medium supplemented with $10^{-4} \%$ Ribav-Extra ${ }^{\circledR}$

\section{Cytokinin + auxin combination: mixed impact on Cymbidium organogenesis in vitro}

When CKs were combined with $2.9 \mu \mathrm{M}$ IAA, there was a mixed response on the formation of new organs. Using a PGR-free control, except for KIN (Table 2), which formed a statistically similar number of PLBs per explant (5.0 PLBs/explant) as the control (5.7 PLBs/ explant), significantly fewer PLBs per explant formed when either BA (up to 3.7 PLBs/explant) (Table 1) or TDZ (up to 4.2 PLBs/explant) (Table 3) was used.
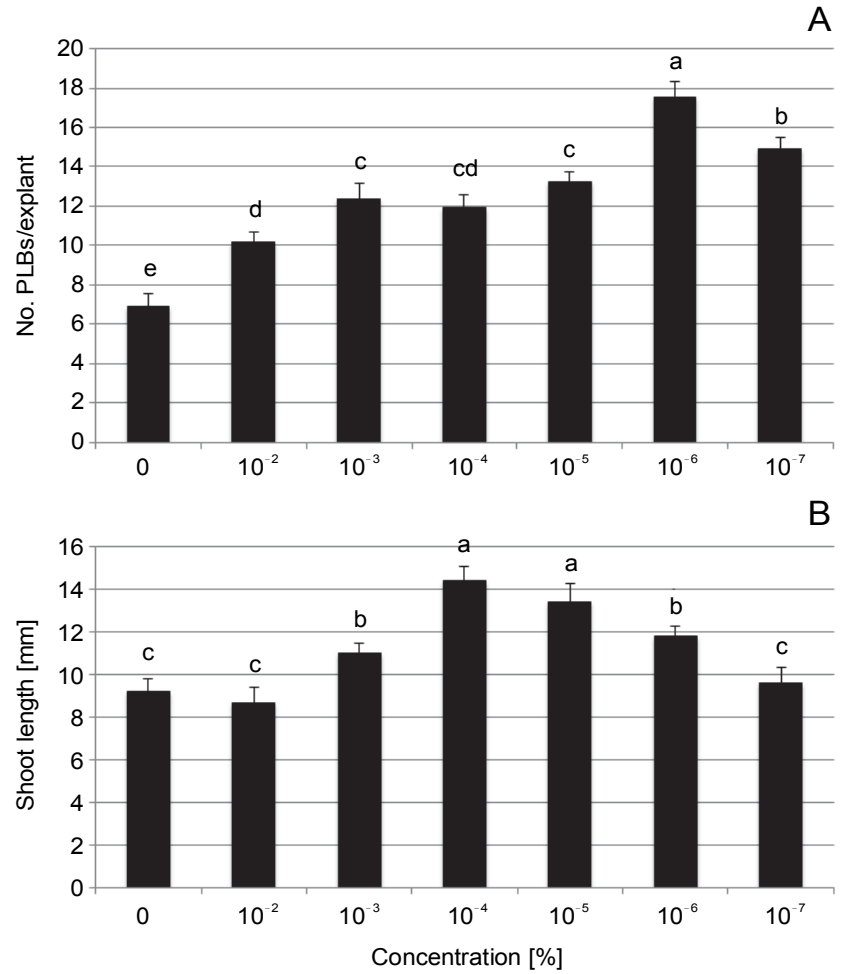

Fig. 3. Effect of varying concentrations of Epin ${ }^{\circledR}$-Extra in MS medium on Cymbidium hybridum organogenesis in vitro; bars indicate SE; different letters indicate significant differences at $P \leq 0.05$ (Tukey's multiple range test, $n=10$ )
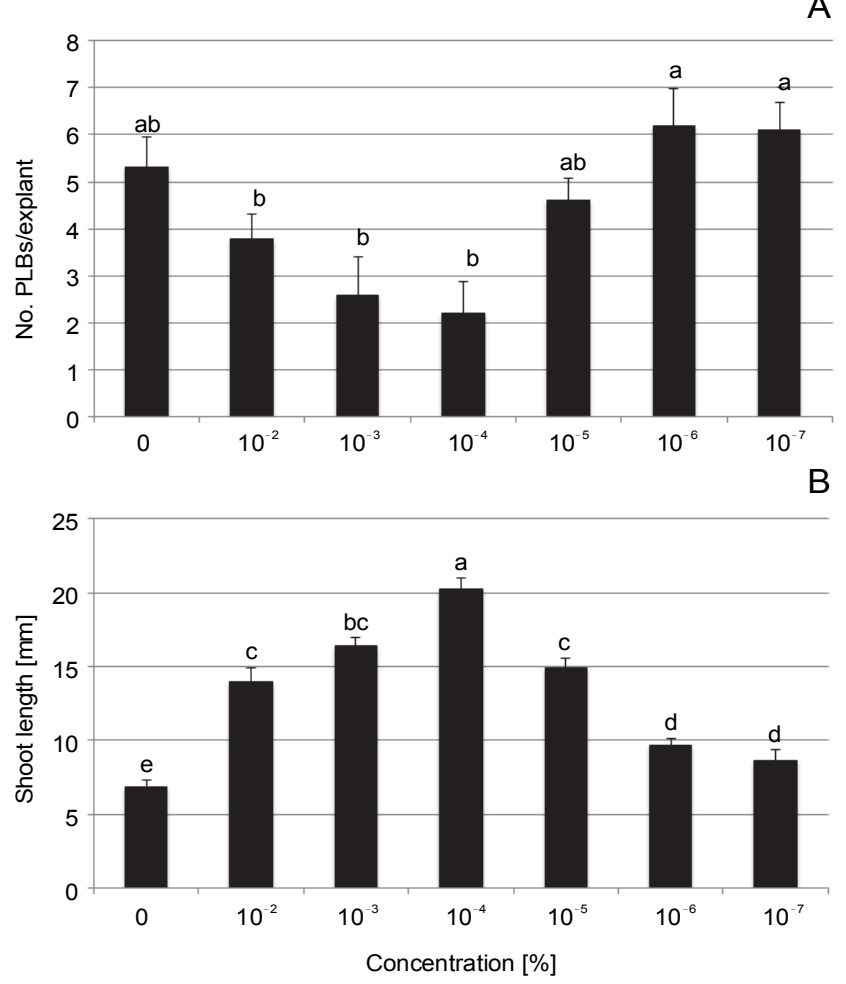

Fig. 4. The effect of different concentrations of Ribav-Extra ${ }^{\circledR}$ on Cymbidium hybridum organogenesis in vitro; bars indicate SE; different letters indicate significant differences at $P \leq 0.05$ (Tukey's multiple range test, $n=10$ ) 

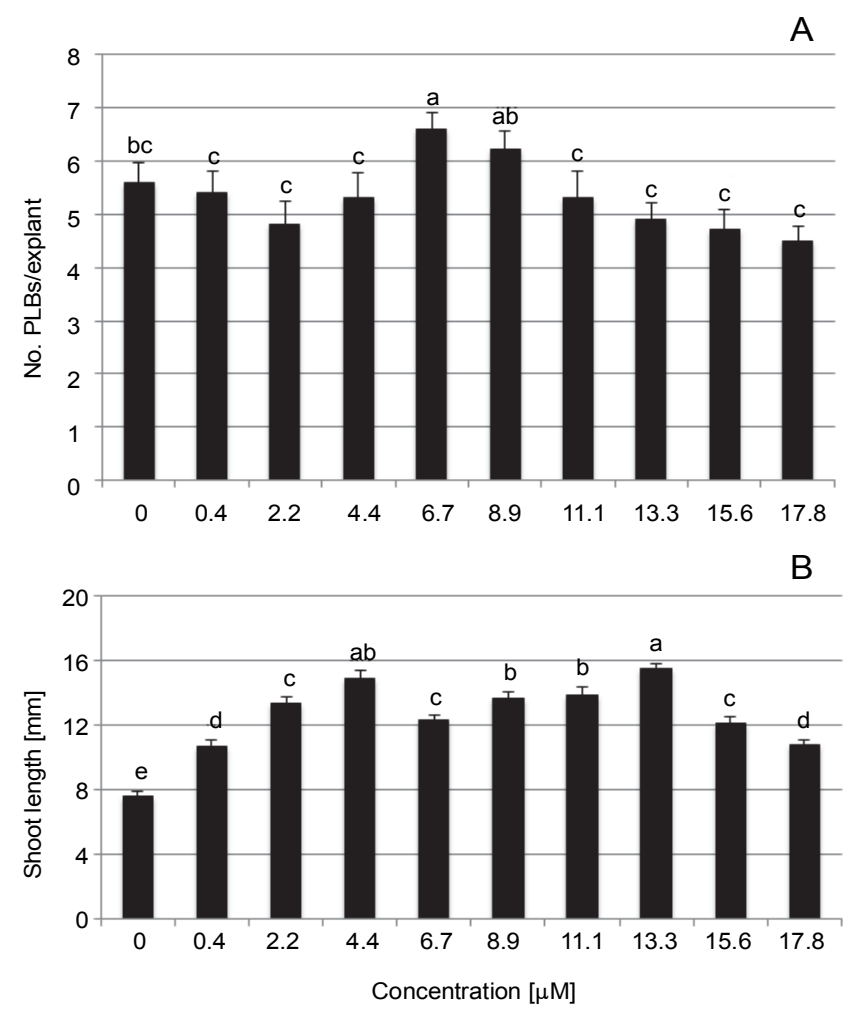

Fig. 5. Effect of different BA concentrations on hybrid $C y m b i$ dium "Memoria Amelia Earhart" organogenesis in vitro; bars indicate SE; different letters indicate significant differences at $P \leq 0.05$ (Tukey's multiple range test, $n=10$ )

However, in combination with IAA, either $2.2 \mu \mathrm{M}$ BA or $0.5 \mu \mathrm{M}$ KIN formed significantly larger PLBs $(3.8 \mathrm{~mm}$ and $4.5 \mathrm{~mm}$ ) than the PGR-free control $(2.0 \mathrm{~mm})$. TDZ, in combination with IAA, formed significantly more shoots per explant than the control (4.0 vs 1.7 shoots/ explant), but the shoots were significantly shorter ( $\max$ $6.0 \mathrm{~mm}$ vs $7.3 \mathrm{~mm}$ ) (Table 1 and Table 2).

\section{Influence of IAA concentration on rooting and acclimatization}

The control plants that were treated with water showed very low survival (about 10\%), and the survival rate of regenerated plants depended on the concentration of IAA and the exposure period to IAA. The most effective period with $60 \%$ survival was observed when plants were treated with $5.7 \mu \mathrm{M}$ IAA for $15 \mathrm{~min}$ (Fig. 6). Acclimatized plants showed robust root and shoot growth (Fig. 7).

\section{Discussion}

Since the Orchidaceae is the largest among all plant species and has very decorative plants, species propaga- tion is important, and biotechnological in vitro methods are essential (Sarmah et al., 2017). Cymbidium has multiple hybrids and cultivars, so propagation protocols for each can be extremely diverse. The optimization of micropropagation protocols for Cymbidium species, hybrids, and varieties depends on both the genotype and the growth and medium conditions. For example, 12 different basal medium formulations induced organogenesis (PLB formation, callus proliferation, or shoot and root development) to different extents with the most effective being full-strength MS (Teixeira da Silva et al., 2005). Because the primary pathways employed in $\mathrm{Cym}_{\mathrm{y}}$ bidium micropropagation involve PLBs and de novo shoot formation, in this study, we assessed the effect of MS medium dilutions and novel PGRs on the in vitro organogenesis of a hybrid Cymbidium cultivar for which no in vitro protocol has been established to date.

The dilutions of MS medium had a positive effect on the number of organs formed in Cymbidium (Fig. 1A), and the differences relative to full-strength MS were significant in all cases except for the number of roots in $1 / 8$ MS. The number of PLBs was almost the same when $1 / 2,1 / 4$, and $1 / 8 \mathrm{MS}$ was used, while shoot number and root number were maximum in $1 / 2$ and $1 / 4 \mathrm{MS}$, respectively. A reduction in MS medium salts, as a result of dilutions, can lead to a stress in explants, which then respond by forming more organs. However, shoot length was proportional to MS dilution and became shorter with a reduction in basal medium strength (Fig. 1B). This might be because of the limitation of a trophic factor (mineral nutrition), which would inhibit shoot growth. In contrast, root growth (length) was not inhibited when MS medium was diluted; moreover, in $1 / 2 \mathrm{MS}$, significantly longer roots were observed (Fig. 1B). This suggests that, unlike shoots, mineral nutrition was not limited; therefore, in the clonal micropropagation of this Cymbidium hybrid ("Memoria Amelia Earhart"), maximum PLB formation and shoot formation was observed for diluted MS, but the best shoot growth occurred when full-strength MS was used. However, Teixeira da Silva et al. (2005) reported that maximum PLB induction in several other Cymbidium hybrids was optimal in fullstrength MS, reflecting genotypic differences (or epigenetic characteristics) of some species or cultivars.

PGRs play a major role in Cymbidium organogenesis and CKs such as BA, KIN, and TDZ, along with auxins such as IAA and NAA, are involved in this process 
Table 1. Effect of various concentrations of BA (with $2.9 \mu \mathrm{M}$ IAA) on Cymbidium hybridum organogenesis

\begin{tabular}{l|c|c|c|c}
\hline $\begin{array}{c}\text { Concentration } \\
{[\mu \mathrm{M}]}\end{array}$ & $\begin{array}{c}\text { PLBs per explant } \\
{[\text { no. }]}\end{array}$ & $\begin{array}{c}\text { PLB size } \\
{[\mathrm{mm}]}\end{array}$ & $\begin{array}{c}\text { Shoots per explant } \\
{[\text { no. }]}\end{array}$ & $\begin{array}{c}\text { Shoot length } \\
{[\mathrm{mm}]}\end{array}$ \\
\hline $0($ PGR-free) & $5.7 \pm 0.3^{\mathrm{a}}$ & $2.0 \pm 0.2^{\mathrm{bc}}$ & $1.7 \pm 0.2^{\mathrm{a}}$ & $7.3 \pm 0.2^{\mathrm{a}}$ \\
\hline 0.4 & $1.3 \pm 0.3^{\mathrm{d}}$ & $1.0 \pm 0.4^{\mathrm{c}}$ & $0.5 \pm 0.1^{\mathrm{d}}$ & $3.0 \pm 0.1^{\mathrm{c}}$ \\
\hline 2.2 & $1.4 \pm 0.2^{\mathrm{d}}$ & $3.8 \pm 0.6^{\mathrm{ab}}$ & $1.0 \pm 0.2^{\mathrm{c}}$ & $7.7 \pm 0.3^{\mathrm{a}}$ \\
\hline 4.4 & $2.3 \pm 0.4^{\mathrm{cd}}$ & $2.9 \pm 0.3^{\mathrm{b}}$ & $1.1 \pm 0.1^{\mathrm{c}}$ & $5.5 \pm 0.3^{\mathrm{b}}$ \\
\hline 6.7 & $3.7 \pm 0.1^{\mathrm{b}}$ & $2.3 \pm 0.2^{\mathrm{b}}$ & $1.1 \pm 0.1^{\mathrm{c}}$ & $4.5 \pm 0.6^{\mathrm{b}}$ \\
\hline 8.9 & $3.2 \pm 0.3^{\mathrm{bc}}$ & $2.0 \pm 0.4^{\mathrm{bc}}$ & $1.3 \pm 0.2^{\mathrm{b}}$ & $3.5 \pm 0.3^{\mathrm{b}}$ \\
\hline 11.1 & $2.9 \pm 0.6^{\mathrm{c}}$ & $1.4 \pm 0.2^{\mathrm{c}}$ & $2.0 \pm 0.1^{\mathrm{a}}$ & $2.3 \pm 0.3^{\mathrm{d}}$ \\
\hline 13.3 & $2.6 \pm 0.3^{\mathrm{c}}$ & $1.4 \pm 0.1^{\mathrm{c}}$ & $1.5 \pm 0.1^{\mathrm{b}}$ & $2.0 \pm 0.1^{\mathrm{d}}$ \\
\hline 15.6 & $2.3 \pm 0.3^{\mathrm{cd}}$ & $1.2 \pm 0.2^{\mathrm{c}}$ & $1.3 \pm 0.1^{\mathrm{b}}$ & $1.7 \pm 0.3^{\mathrm{d}}$ \\
\hline 17.8 & $2.3 \pm 0.4^{\mathrm{cd}}$ & $1.0 \pm 0.2^{\mathrm{c}}$ & $1.0 \pm 0.2^{\mathrm{c}}$ & $1.5 \pm 0.1^{\mathrm{e}}$ \\
\hline
\end{tabular}

Different letters within each column indicate significant differences $(P \leq 0.05$; Tukey's multiple range test; $n=10)$

Table 2. Effect of various concentrations of KIN (with $2.9 \mu \mathrm{M} \mathrm{IAA)} \mathrm{on} \mathrm{Cymbidium} \mathrm{hybridum} \mathrm{organogenesis}$

\begin{tabular}{l|c|c|c|c}
\hline $\begin{array}{c}\text { Concentration } \\
{[\mu \mathrm{M}]}\end{array}$ & $\begin{array}{c}\text { PLBs per explant } \\
{[\text { no. }]}\end{array}$ & $\begin{array}{c}\text { PLB size } \\
{[\mathrm{mm}]}\end{array}$ & $\begin{array}{c}\text { Shoots per explant } \\
{[\text { no. }]}\end{array}$ & $\begin{array}{c}\text { Shoot length } \\
{[\mathrm{mm}]}\end{array}$ \\
\hline $0($ PGR-free) & $5.7 \pm 0.2^{\mathrm{a}}$ & $2.0 \pm 0.1^{\mathrm{c}}$ & $1.7 \pm 0.2^{\mathrm{a}}$ & $7.3 \pm 0.2^{\mathrm{a}}$ \\
\hline 0.5 & $1.0 \pm 0.1^{\mathrm{d}}$ & $4.5 \pm 0.3^{\mathrm{a}}$ & $0.5 \pm 0.1^{\mathrm{c}}$ & $2.0 \pm 0.1^{\mathrm{c}}$ \\
\hline 2.3 & $1.0 \pm 0.1^{\mathrm{d}}$ & $3.0 \pm 0.1^{\mathrm{b}}$ & $0.7 \pm 0.2^{\mathrm{b}}$ & $2.5 \pm 0.3^{\mathrm{b}}$ \\
\hline 4.7 & $1.3 \pm 0.2^{\mathrm{d}}$ & $2.3 \pm 0.1^{\mathrm{bc}}$ & $1.0 \pm 0.1^{\mathrm{b}}$ & $2.7 \pm 0.2^{\mathrm{b}}$ \\
\hline 7.0 & $2.0 \pm 0.5^{\mathrm{d}}$ & $2.0 \pm 0.4^{\mathrm{c}}$ & $0.8 \pm 0.1^{\mathrm{b}}$ & $2.1^{\mathrm{b}} 0.1^{\mathrm{c}}$ \\
\hline 9.3 & $3.4 \pm 0.2^{\mathrm{c}}$ & $1.5 \pm 0.1^{\mathrm{c}}$ & $0^{\mathrm{d}}$ & $0^{\mathrm{d}}$ \\
\hline 11.6 & $5.0 \pm 0.3^{\mathrm{a}}$ & $1.1 \pm 0.4^{\mathrm{d}}$ & $0^{\mathrm{d}}$ & $0^{\mathrm{d}}$ \\
\hline 14.0 & $4.5 \pm 0.2^{\mathrm{a}}$ & $1.1 \pm 0.3^{\mathrm{d}}$ & $0^{\mathrm{d}}$ & $0^{\mathrm{d}}$ \\
\hline 16.3 & $4.0 \pm 0.1^{\mathrm{b}}$ & $1.1 \pm 0.1^{\mathrm{d}}$ & $0^{\mathrm{d}}$ & $0^{\mathrm{d}}$ \\
\hline 18.6 & $1.5 \pm 0.3^{\mathrm{d}}$ & $0.5 \pm 0.2^{\mathrm{e}}$ & $0^{\mathrm{d}}$ & $0^{\mathrm{d}}$ \\
\hline
\end{tabular}

Different letters within each column indicate significant differences $(P \leq 0.05 ;$ Tukey's multiple range test; $n=10)$

(Ghosh et al., 2014; Sarmah et al., 2017). In Cymbidium micropropagation, CKs are generally used to promote PLB proliferation, axillary branching, and shoot elongation (Teixeira da Silva et al., 2006b), although the optimal CK concentration varies with the genotype used while higher $\mathrm{CK}$ concentrations inhibit shoot growth (Paek and Yeung, 1991; Chang and Chang, 2000a; Lu et al., 2001). Although CKs reduced the growth and number of shoots in Cymbidum forrestii, BA was able to induce shoots in vitro at $5 \mathrm{mg} \cdot \mathrm{dm}^{3}$ (Paek and Yeung, 1991). Moreover, BA at $0.5 \mathrm{mg} \cdot \mathrm{dm}^{3}$ inhibited shoot elongation and root growth in Cymbidium ensifolium "Yuh Hwa", and BA supplied at $5 \mathrm{mg} \cdot \mathrm{dm}^{3}$ was sufficient to induce shoots but not shoot elongation ( $\mathrm{Lu}$ et al., 2001). Cymbidium sinense Willd initiated shoot buds in the presence of $0.01-1 \mathrm{mg} \cdot \mathrm{dm}^{3} \mathrm{TDZ}$, although TDZ retarded rhizome proliferation (Chang and Chang, 2000). TDZ has multiple detrimental effects in plant in vitro culture (Dewir et al., 2018). In our study, BA itself stimulated the formation of more PLBs per explant at $6.7 \mu \mathrm{M}$ and shoot length at $4.4 \mu \mathrm{M}$ and $13.3 \mu \mathrm{M}$ (Fig. 5A and Fig. 5B). However, CK in combination with IAA had 
Table 3. Effect of various TDZ concentrations (with $2.9 \mu \mathrm{M}$ IAA) on Cymbidium hybridum organogenesis

\begin{tabular}{l|c|c|c|c}
\hline $\begin{array}{c}\text { Concentration } \\
{[\mu \mathrm{M}]}\end{array}$ & $\begin{array}{c}\text { PLBs per explant } \\
{[\text { no. }]}\end{array}$ & $\begin{array}{c}\text { PLB size } \\
{[\mathrm{mm}]}\end{array}$ & $\begin{array}{c}\text { Shoots per explant } \\
{[\text { no. }]}\end{array}$ & $\begin{array}{c}\text { Shoot length } \\
{[\mathrm{mm}]}\end{array}$ \\
\hline $0($ PGR-free $)$ & $5.7 \pm 0.2^{\mathrm{a}}$ & $2.0 \pm 0.2^{\mathrm{a}}$ & $1.7 \pm 0.1^{\mathrm{b}}$ & $7.3 \pm 0.2^{\mathrm{a}}$ \\
\hline $0.000000001^{*}$ & $1.0 \pm 0.4^{\mathrm{d}}$ & $1.2 \pm 0.3^{\mathrm{b}}$ & $4.0 \pm 0.01^{\mathrm{a}}$ & $1.5 \pm 0.1^{\mathrm{f}}$ \\
\hline 0.0000001 & $1.5 \pm 0.3^{\mathrm{d}}$ & $1.2 \pm 0.2^{\mathrm{b}}$ & $1.8 \pm 0.1^{\mathrm{b}}$ & $3.1 \pm 0.2^{\mathrm{d}}$ \\
\hline 0.00001 & $2.0 \pm 0.3^{\mathrm{d}}$ & $1.3 \pm 0.1^{\mathrm{b}}$ & $1.5 \pm 0.2^{\mathrm{bc}}$ & $5.0 \pm 0.3^{\mathrm{c}}$ \\
\hline 0.001 & $2.5 \pm 0.3^{\mathrm{cd}}$ & $1.4 \pm 0.2^{\mathrm{ab}}$ & $1.3 \pm 0.01^{\mathrm{c}}$ & $6.0 \pm 0.2^{\mathrm{b}}$ \\
\hline 0.1 & $2.7 \pm 0.3^{\mathrm{cd}}$ & $1.4 \pm 0.3^{\mathrm{a}}$ & $1.0 \pm 0.03^{\mathrm{d}}$ & $3.0 \pm 0.01^{\mathrm{d}}$ \\
\hline 1 & $3.4 \pm 0.3^{\mathrm{c}}$ & $1.5 \pm 0.3^{\mathrm{a}}$ & $1.0 \pm 0.1^{\mathrm{d}}$ & $2.1 \pm 0.1^{\mathrm{e}}$ \\
\hline 10 & $4.2 \pm 0.2^{\mathrm{b}}$ & $1.7 \pm 0.3^{\mathrm{a}}$ & $0.5 \pm 0.1^{\mathrm{e}}$ & $1.0 \pm 0.15^{\mathrm{g}}$ \\
\hline 100 & $3.5 \pm 0.3^{\mathrm{c}}$ & $0.8 \pm 0.1^{\mathrm{c}}$ & $0^{\mathrm{f}}$ & $00^{\mathrm{h}}$ \\
\hline
\end{tabular}

Different letters within each column indicate significant differences $(P \leq 0.05$; Tukey's multiple range test; $n=10)$; * previous initial trials indicated that low concentrations, as low as $10^{-15} \mathrm{M}$, could affect organogenesis, so this low concentration was tested

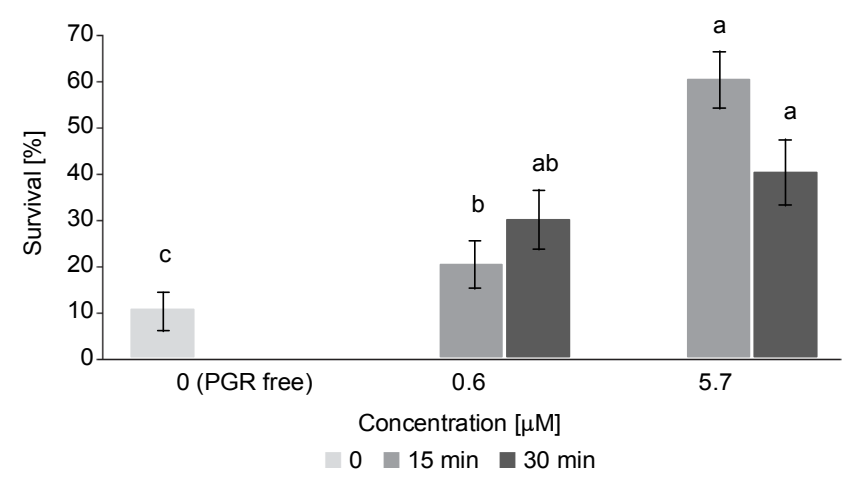

Fig. 6. The effect of IAA concentration and exposure period on the survival rate of regenerated plants of hybrid $C y m b i$ dium "Memoria Amelia Earhart"; different letters across all concentrations indicate significant differences at $P \leq 0.05$

(Tukey's multiple range test); $n=10$

no positive effect on PLB formation but influenced the formation and length of shoots (Tables 1-3). KIN, unlike other CKs, promoted an increase in PBL size (Table 2).

The presence of CKs and auxins in basal medium is a common practice for micropropagating orchids (Teixeira da Silva, 2013a; Sarmah et al., 2017). Broadly, the micropropagation of several orchid species can be achieved when full-strength MS is supplemented with NAA $\left(0.1-5.0 \mathrm{mg} \cdot \mathrm{dm}^{3}\right)$, BA $\left(0.1-2.5 \mathrm{mg} \cdot \mathrm{dm}^{3}\right)$, or TDZ $(4.54$ $-18.16 \mathrm{mg} \cdot \mathrm{dm}^{3}$ ) (Sarmah et al., 2017). The highest frequency of secondary protocorm induction (96\%) in a Cymbidium hybrid with a mean of 13.2 secondary protocorms per explant was obtained in full-strength MS

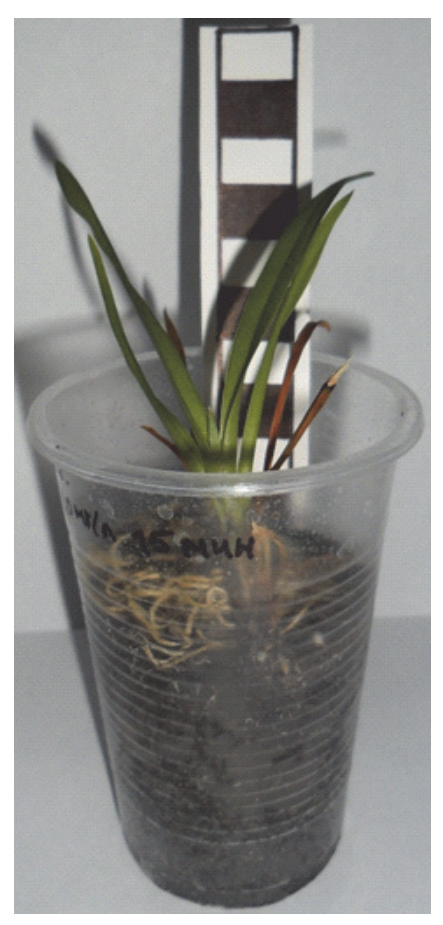

Fig. 7. Acclimatized hybrid Cymbidium "Memoria Amelia Earhart" plant (30-day-old) after treatment with $5.7 \mu \mathrm{M}$ IAA for $15 \mathrm{~min}$; one notch on ruler (black or white) $=1 \mathrm{~cm}$

medium supplemented with $0.3 \mathrm{mg} \cdot \mathrm{dm}^{3} \mathrm{KIN}$ and $0.1 \mathrm{mg} \cdot \mathrm{dm}^{3}$ NAA (Kim et al., 2017).

Park et al. (2018) explored the influence of 2,4-D (5-40 $\mu \mathrm{M}), \mathrm{BA}(1-8 \mu \mathrm{M})$, and TDZ $(1-8 \mu \mathrm{M})$ on direct rhizome induction and shoot formation from the rhizome explants of Cymbidium goeringii. Moreover, direct ad- 
ventitious shoot formation was achieved in full-strength MS medium that incorporated BA or TDZ. The number of adventitious shoots produced per explant (rhizome segment) significantly increased in the presence of $20 \mu \mathrm{M}$ 2,4-D and $2 \mu \mathrm{M}$ TDZ (Park et al., 2018).

Several CKs, auxins, and other PGRs were tested for the micropropagation of another Cymbidium cultivar (Teixeira da Silva, 2014). However, the wide-ranging effects and the lack of PGRs that can result in organogenic outcomes superior to currently optimized protocols calls for a new era in which novel PGRs are welcomed in plant tissue culture. In this study, we document the first ever use of commercial Epin-Extra ${ }^{\circledR}$ (with an 24-EpiB base) and RE as alternative PGRs. Previously, these natural PGRs were used only for seed treatment, spraying plants, or processing cuttings, and these treatments resulted in an enhanced tolerance to abiotic stresses (Lukatkin and Pogodina, 2012; Lukatkin et al., 2013a; 2013b; Bashmakov et al., 2016; Gruznova et al., 2018). We also showed that these PGRs may be used as alternative PGRs in the in vitro culture of carnation (Dianthus caryophyllus L.) (Lukatkin et al., 2017). However, the concentration dependence of these PGRs greatly varies in different experiments, and readers should be aware that the timing of sampling will affect the outcome of organogenesis as was reported for hybrid Cymbidium (Teixeira da Silva and Dobránszki, 2013).

The pretreatment of maize (Zea mays L.) seeds with $10^{-8}-10^{-11} \mathrm{M} 24-\mathrm{EpiB}$ stimulated seed germination and seedling growth after treatment with heavy metals (zinc and nickel) and reduced heavy metal-induced electrolyte leakage from cells (Lukatkin et al., 2013a). Similarly, the pretreatment of bread wheat (Triticum aestivum L.) seeds with $1.0 \mu \mathrm{M} 24-\mathrm{EpiB}$ protected seedlings from the negative impacts of heavy metals $(\mathrm{Cu}, \mathrm{Pb}, \mathrm{Ni}, \mathrm{Zn}$, or $\mathrm{Sr})$, diminished oxidative stress and improved overall growth (Bashmakov et al., 2016). 24-EpiB increased catalase activity and subsequently controlled cellular $\mathrm{O}_{2 .-}$ and lipid peroxidation; therefore, it may be a plausible mechanism that eventually resulted in 24-EpiB-mediated improved root and shoot growth traits in wheat plants (Bashmakov et al., 2016). Similarly, Epin-Extra ${ }^{\circledR}$ had a positive effect on young maize plants affected by cold stress $\left(3^{\circ} \mathrm{C}\right)$ and heat stress $\left(43^{\circ} \mathrm{C}\right)$, and the most effective 24-EpiB concentrations maximizing thermal resistance of maize seedlings were $10^{-9}$ and $10^{-10} \mathrm{M}$ for $3^{\circ} \mathrm{C}$ and $43^{\circ} \mathrm{C}$, respectively (Lukatkin et al., 2013b). However, the optimum concentration of $24-\mathrm{EpiB}$ in carnation micropropagation was $10^{-3} \%$ for shoot growth, shoot multiplication, and number of internodes per shoot (Lukatkin et al., 2017).

Similar data were obtained when we used RE. A presowing treatment of wheat seeds with RE (10 ppm or $10^{-3} \%$ ) decreased the negative impact of heavy metals $(\mathrm{Cu}, \mathrm{Zn}, \mathrm{Ni}$, or $\mathrm{Pb})$ by reducing oxidative stress by suppressing $\mathrm{O}_{2 .-}$ generation, lipid peroxidation intensity, and catalase activity. This suggests that wheat plants whose seeds had been treated with RE were more heavy metal-resistant than untreated plants (Gruznova et al., 2018). The treatment of maize seeds with $\mathrm{RE}$ changed parameters related to oxidative stress (the generation of superoxide anion and the intensity of lipid peroxidation) and stimulated increased antioxidative activity in maize seedlings under unfavorable temperatures. The best results were noted at a nano-concentration of $\mathrm{RE}(1 \mathrm{nl} / \mathrm{l}$ or $10^{-7} \%$ ) (Lukatkin and Pogodina, 2012). The maximum positive effect of RE supplementation to basal media in clonally propagated in vitro carnation was obtained at $10^{-5} \%$, which stimulated shoot growth, or $10^{-6} \%$, which increased the number of internodes per shoot (Lukatkin et al., 2017).

The most novel finding of this study is that PLB formation was enhanced by $24-\mathrm{EpiB}$ compared to BA and that RE was ineffective. However, shoot growth was significantly enhanced by RE, and much more by BA or 24-EpiB. Moreover, no additional rooting step was required and rooting was spontaneous from PLBs, which is a general response of hybrid Cymbidium PLBs that are derived from treatments with these PGRs. This makes the protocol simpler than those previously published (Teixeira da Silva, 2013a). These are new and important findings for improving hybrid Cymbidium growth in vitro. Studies on the use of RE and EpinExtra ${ }^{\circledR}$ for plant in vitro studies provide a new and exciting area of research for which no literature exists.

In vitro organogenesis (PLB and shoot induction) of the Cymbidium hybrid "Memoria Amelia Earhart" depends on the dilution of MS (in contrast, the optimum shoot growth requires a full-strength MS) and on the choice of PGRs. Acclimatization (60\%) of this cultivar was possible when plants were treated with $5.7 \mu \mathrm{M}$ IAA for $15 \mathrm{~min}$. 


\section{Acknowledgment}

This work was supported by the Ministry of Education and Science of the Russian Federation (project No. 6.783.2014K).

\section{References}

Albert N.W., Arathoon S., Collette V.E., Schwinn K.E., Jameson P.E., Lewis D.H., Zhang H., Davies K.M. (2010) Activation of anthocyanin synthesis in Cymbidium orchids: variability between known regulators. Plant Cell Tiss. Organ Cult. 100: 355-360.

Bashmakov D.I., Gruznova K.A., Lukatkin A.S., Anjum N.A., Pereira E. (2016) Assessment of divalent metal-toxicity and the role of 24-epibrassinolide in Triticum aestivum seedlings. Aperito J. Adv. Plant Biol. 2 (1): 107.

Chang C., Chang W.C. (1998) Plant regeneration from callus culture of Cymbidium ensifolium var. misericors. Plant Cell Rep. 17: 251-255

Chang C., Chang W.C. (2000) Effect of thidiazuron on bud development of Cymbidium sinense Wild in vitro. Plant Growth Regul. 30:171-175.

Dewir Y.H., Nurman S., Naidoo Y., Teixeira da Silva J.A. (2018) Thidiazuron-induced abnormalities in plant tissue cultures. Plant Cell Rep. 37:1451-1470.

Fonnesbech M. (1972) Growth hormones and propagation of Cymbidium in vitro. Physiol. Plant. 27: 310-316.

Ghosh A., Hossain M.M., Sharma M. (2014) Mass propagation of Cymbidium giganteum Wall. ex Lindl. using in vitro seedlings. Indian J. Exp. Biol. 52: 905-911.

Gruznova K.A., Bashmakov D.I., Miliauskienė J., Vaštakaitè V., Duchovskis P., Lukatkin A.S. (2018) The effect of a growth regulator Ribav-Extra on winter wheat seedlings exposed to heavy metals. Zemdirbyste-Agricult. 105(3): 227-234.

Hossain M.M., Sharma M., Teixeira da Silva J.A., Pathak P. (2010) Seed germination and tissue culture of Cymbidium giganteum Wall. ex Lindl. Sci. Hortic. 123: 479-487.

Hossain M.M., Kant R., Van P.T., Winarto B., Zeng S.J., Teixeira da Silva J.A. (2013) The application of biotechnology to orchids. Crit. Rev. Plant Sci. 32: 69-139.

Kaur S., Bhutani K.K. (2012) Organic growth supplement stimulants for in vitro multiplication of Cymbidium pendulum (Roxb.) $S w$. Hortic. Sci. 39: 47-52.

Kim D.H., Kang K.W., Sivanesan I. (2017) In vitro propagation of Cymbidium hybrid. Propag. Ornam. Plants 17(2): 48-54.

Kostenyuk I., Oh B.J., So I.S. (1999) Induction of early flowering in Cymbidium niveo-marginatum Mak in vitro. Plant Cell Rep. 19: 1-5.

Kudryashova O.A., Volotovich A.A., Vasilevskaya T.I., Varavina N.P., Rupasova Zh.A., Khripach V.A. (2012) Effects of 24epibrassinolide on in vitro micropropagation of highbush blueberry. Russ. J. Plant Physiol. 59: 586-593.

Lu I.-L., Sutter E., Burger D. (2001) Relationships between benzyladenine uptake, endogenous free IAA levels and peroxidase activities during upright shoot induction of Cymbidium ensifoilum cv. Yuh Hwa rhizomes in vitro. Plant Growth Regul. 35: 161-170.
Lukatkin A.S., Pogodina D.N. (2012) Efficacy of the protective action of growth regulator Ribav-Extra on maize seedlings under temperature stress. Russ. Agricult. Sci. 38(2): 94-97.

Lukatkin A.S., Kashtanova N.N., Duchovskis P. (2013a) Changes in maize seedlings growth and membrane permeability under the effect of epibrassinolide and heavy metals. Russ. Agricult. Sci. 39(4): 307-310.

Lukatkin A.S., Kashtanova N.N., Duhovskis P. (2013b) Influence of epibrassinolide on the thermal resistance of maize seedlings. Agrochimija 6: 24-31.

Lukatkin A.S., Mokshin E.V., Teixeira da Silva J.A. (2017) Use of alternative plant growth regulators and carbon sources to manipulate Dianthus caryophyllus L. shoot induction in vitro and control hyperhydricity. Rendiconti Lincei 28 (3): 583-588.

Morel G.M. (1960) Producing virus-free Cymbidium. Amer. Orchid Soc. Bull. 29: 495-497.

Murashige T., Skoog F. (1962) A revised medium for rapid growth and bioassays with tobacco tissue cultures. Physiol. Plant. 15: 473-497.

Park H.Y., Kang K.W., Kim D.H., Sivanesan I. (2018) In vitro propagation of Cymbidium goeringii Reichenbach fil. through direct adventitious shoot regeneration. Physiol. Mol. Biol. Plants 24(2): 307-313.

Paek K.Y., Yeung E.C. (1991) The effects of 1-naphthaleneacetic acid and $N^{6}$-benzyladenine on the growth of Cymbidium forrestii rhizomes in vitro. Plant Cell Tiss. Organ Cult. 24: 65-71.

Sarmah D., Kolukunde S., Sutradhar M., Kumar Singh B., Mandal T., Mandal N. (2017) A review on: in vitro cloning of orchids. Int. J. Curr. Microbiol. App. Sci. 6(9): 1909-1927.

Tao J., Yu L.Q., Kong F., Zhao D.Q. (2011) Effects of plant growth regulators on in vitro propagation of Cymbidium faberi Rolfe. Afr. J. Biotechnol. 10: 15639-15646

Teixeira da Silva J.A. (2013a) Orchids: Advances in tissue culture, genetics, phytochemistry and transgenic biotechnology. Floriculture Ornamental Biotechnol 7(1): 1-52.

Teixeira da Silva J.A. (2013b) 24-Epibrassinolide and 28homobrassinolide, two brassinosteroids, inhibit protocormlike body development in hybrid Cymbidium (Orchidaceae). J. Hortic. Forestry Biotechnol. 17: 22-27.

Teixeira da Silva J.A. (2013c) Impact of paper bridges, activated charcoal, and antioxidants on growth and development of protocorm-like bodies of hybrid Cymbidium. In Vitro Cell Dev. Biol. - Plant 49: 414-420.

Teixeira da Silva J.A. (2014) Response of hybrid Cymbidium (Orchidaceae) protocorm-like bodies to 26 plant growth regulators. Bot. Lithuanica 20: 3-13.

Teixeira da Silva J.A., Chan M-T., Sanjaya, Chai M-L., Tanaka M. (2006a) Priming abiotic factors for optimal hybrid Cymbidium (Orchidaceae) PLB and callus induction, plantlet formation, and their subsequent cytogenetic stability analysis. Sci. Hortic. 109: 68-378.

Teixeira da Silva J.A., Dobránszki J. (2013) How timing of sampling can affect the outcome of the quantitative assessment of plant organogenesis. Sci. Hortic. 159: 59-66. 
Teixeira da Silva J.A., Singh N., Tanaka M. (2006b) Priming biotic factors for optimal protocorm-like body and callus induction in hybrid Cymbidium (Orchidaceae), and assessment of cytogenetic stability in regenerated plantlets. Plant Cell Tiss. Organ Cult. 84: 119-128.

Teixeira da Silva J.A., Tanaka M. (2006) Multiple regeneration pathways via thin cell layers in hybrid Cymbidium (Orchidaceae). J. Plant Growth Reg. 25: 203-210.

Teixeira da Silva J.A., Yam T., Fukai S., Nayak N., Tanaka M. (2005) Establishment of optimum nutrient media for in vitro propagation of Cymbidium $S_{W}$. (Orchidaceae) using protocorm-like body segments. Propagation Ornam. Plants 5: 129-136.

Vardhini B.V., Anjum N.A. (2015) Brassinosteroids make plant life easier under abiotic stresses mainly by modulating major components of antioxidant defense system. Front. Environ. Sci. 2: 67.

Yu J., Ahammed, G., Krishna, P. (2019) Brassinosteroids in Plant Developmental Biology and Stress Tolerance. Academic Press, Cambridge, MA, USA, 400 pp. 